Received: 7 April 2017

Accepted: 12 July 2017

Published online: 22 September 2017

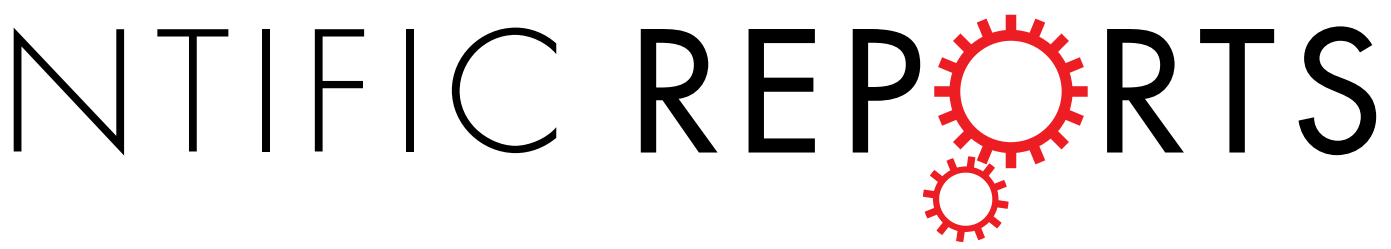

\title{
OPEN Altered brain activity and the effect of personality traits in excessive smartphone use during facial emotion processing
}

\author{
Ji-Won Chun ${ }^{1}$, Jihye Choi ${ }^{1}$, Jin-Young Kim ${ }^{1}{ }^{1}$, Hyun Cho ${ }^{1}$, Kook-Jin Ahn ${ }^{2}$, Jong-Ho Nam ${ }^{3}$, \\ Jung-Seok Choi ${ }^{4}$ \& Dai-Jin Kim ${ }^{1}$
}

Excessive smartphone use is a phenomenon related to maladaptive smartphone use, leading to negative consequences. This study set out with the aim of assessing the effects of excessive smartphone use on behavioral and neural responses during facial emotional processing. We examined 25 excessive smartphone users and 27 normal control users using functional MRI during facial emotion processing and investigated Behavioral Inhibition System/Behavioral Activation System (BIS/BAS). The excessive smartphone use group (SP) showed neural deactivation in the dorsolateral prefrontal cortex (DLPFC) and dorsal anterior cingulate cortex (dACC) during the presentation of an angry face and emotional transition compared to that of the normal control group (NC). Additionally, the SP revealed neural deactivation of the superior temporal sulcus and temporo-parietal junction related to social interaction during emotional transition compared to the NC. We found that BAS-Reward Responsiveness level was correlated with behavioral responses during repeated happy faces related to emotional reward in SP compared to NC. It can thus be suggested that excessive smartphone use is likely to fail on cognitive control during emotional processing, and this impairment might be influenced on emotional processing related to social interaction.

Over the past decade, smartphones have become a necessity for people's daily lives with the development of technology. Despite many positive aspects, excessive mobile phone use often leads to potentially harmful or disturbing behaviors such as uncontrolled use leading to a negative impact on various aspects of daily life ${ }^{1}$, and thus, problematic mobile phone use has raised sufficient concerns for being considered a potential public health issue $^{2}$. People who are addicted to smartphone use are unable to maintain concentration on a task or in interpersonal relationships due to the need to constantly check mobile phone notifications ${ }^{3}$. Additionally, the tendency to be emotionally vulnerable ${ }^{4-6}$ and have low levels of self-esteem ${ }^{4,7,8}$ is known to be associated with increased smartphone addiction. In the study using neuroimaging, college students with mobile phone dependence showed altered gray matter volume and white matter integrity ${ }^{9}$. In the previous study using exploratory factor analysis, smartphone addiction symptoms were identified that disregarding of harmful consequences, preoccupation, inability to control craving, productivity loss, and feeling anxious and lost ${ }^{10}$. Particularly, lonely and depressed people preference interacting with other people by texting or social networking applications ${ }^{10,11}$ and these pattern leads to negative outcomes related to their Internet use ${ }^{11}$. Also, previous study using Internet questionnaire identified that lonely participants preferred making voice calls and anxious participants preferred texting ${ }^{12}$. Therefore, it would be suggested that individual's emotion influence on excessive smartphone use associated with social interaction.

Although excessive smartphone use did not define clinical criteria for disorder, excessive smartphone use shares similar sub-dimension with addiction criteria of DSM $5^{13,14}$. In particular, the negative aspects of excessive smartphone use share the same effects as Internet addiction including Internet gaming addiction on interpersonal

${ }^{1}$ Department of Psychiatry, Seoul St. Mary's Hospital, The Catholic University of Korea College of Medicine, Seoul, Republic of Korea. 'Department of Radiology, Seoul St. Mary's Hospital, The Catholic University of Korea College of Medicine, Seoul, Republic of Korea. ${ }^{3}$ Department of Psychology, The Catholic University of Korea, Seoul, Republic of Korea. ${ }^{4}$ Department of Psychiatry, SMG-SNU Boramae Center, Seoul, Republic of Korea. Correspondence and requests for materials should be addressed to D.-J.K. (email: kdj922@catholoc.ac.kr) 
interaction ${ }^{15}$. In previous studies, Internet addiction and pathological Internet use have been shown to lead to negative outcomes including uncontrolled Internet use, tolerance, withdrawal, social isolation and poor academic or professional achievement ${ }^{16,17}$. However, the study of smartphone addiction as a potential psychiatric disorder is in its infancy, and the evidence supporting problematic smartphone use as an addictive behavior is still insufficient ${ }^{1}$.

Problematic smartphone use have related to individual's social interaction. In previous studies, people using SNS more in terms of time spent usage were found to be less involved in the real life community ${ }^{18}$, and individuals who did not feel comfortable with their peers in real life tend to use social networking service (SNS) more in order to compensate ${ }^{19}$. In some studies, the negative consequences of using SNS use considered as criteria for substance dependence, and these might be considered as valid criteria for behavioral addiction ${ }^{20}$. Addiction influence on the brain's neuronal circuits necessary for not only reward and motivation, but also social behaviors, and thus allows addicted individuals to make poor choices despite awareness of the negative outcomes ${ }^{21}$. Internet addiction criteria of DSM 5 have included social isolation, and previous studies related to Internet addiction, Internet gaming addiction, and smartphone addiction have considered important role of social interaction or interpersonal relationship on addiction ${ }^{11,22,23}$. It is necessary to take account of individual's personality traits in order to understand characteristic of social interaction in smartphone addiction. In particular, personality traits related to emotional processing are key to understanding social interaction.

It is known that the behavioral inhibition (BIS) and behavioral activation (BAS) systems are closely related not only to temperament and personality traits but also to a wide range of affective experiences ${ }^{24}$. The BAS are associated with positive emotional and extroversion, whereas BIS are closely related to negative emotional and emotional instability ${ }^{25}$. Furthermore, BAS and BIS are explained on the basis of the independent and distinctive structures in the nervous system and behavioral patterns ${ }^{26}$. According to Gray's theory, the BIS/BAS systems are theoretical biopsychological systems related to personality traits involving sensitivity toward stimuli associated with negative and positive reinforcement and regulation of motivational behavior ${ }^{27-29}$. In particular, it is reported that BIS is sensitive to punishment and non-reward cues in terminating behavioral output, and BAS is not only sensitive to reward cues and activating goal directed behavior ${ }^{28,30,31}$, but also likely to promote the experience of positive feelings such as exaltation and happiness ${ }^{24}$. Additionally, BAS are considered to be personality factors associated with Internet addiction ${ }^{32,33}$ and smartphone dependency ${ }^{14,34}$. In previous studies, BAS activity is associated with substances use such as alcohol ${ }^{35-37}$. It has been reported that BIS and BAS were associated with the neural activity in the lateral prefrontal cortex ${ }^{38}$ and dorsal anterior cingulate cortex (dACC) ${ }^{39}$ related to cognitive control. Therefore, it can be supposed that individual personality traits in excessive smartphone use have an influence on behavioral and neural response for social reward cue.

In this study, we have designed a task to explore altered brain activity in excessive smartphone use during cognitive control of an emotional face. In previous studies, a facial emotion discrimination task has been generally used to study social interaction ${ }^{40,41}$. The perception of changes due to facial movements plays a more central role in social communication ${ }^{41}$. In previous studies, an increased level of general anxiety, including social anxiety, is related to excessive smartphone use $\mathrm{e}^{8,42,43}$, and socially anxious individuals revealed attentional biases toward threatening stimuli, especially angry faces ${ }^{44}$. In previous neuroimaging studies, the dorsolateral prefrontal cortex (DLPFC) and dACC have been shown to be engaged in cognitive control and emotional regulation ${ }^{45-49}$. Previous studies using animal models of affective learning and imaging studies of either cognitive control or emotional responding in both healthy and psychiatric populations have implicated regions of the prefrontal cortex (PFC) and anterior cingulate cortex (ACC $)^{50-53}$. The DLPFC may be more involved in maintaining a representation of the context, such as goals, rules and sequence of events, necessary to perform a task accurately ${ }^{54,55}$. Additionally, the ACC has been shown to be activated by the manipulation of interference and cognitive loading in a previous study related to working memor ${ }^{54}$. Activation of this region is thought to be related to detecting cognitive conflict and signaling the need for greater allocation of attention for the purpose of resolving conflict ${ }^{56-58}$.

In this study, we will focus on identifying altered brain activity involved in social interaction in those with excessive smartphone use. Although the relationship between excessive smartphone use and social interaction has been reported ${ }^{19,20}$, no evidence has been found proving altered neural activity of social emotion in excessive smartphone use. Therefore, we investigated the differences in the behavioral and neural responses between the excessive smartphone use group (SP) and the normal control group (NC) in the cognitive control of facial expressions in order to find neurobiological evidence of excessive smartphone use affecting social interaction. Additionally, this study tends to investigate the influence of personality trait related reward system on the emotional processing due to social context in excessive smartphone use. We examined the correlations between BAS reward response and the behavioral and neural responses related to facial emotion processing in the SP compared with NC.

This study investigated the effect of excessive smartphone use on neural activity during facial emotion discrimination through the following hypothesis. First, we hypothesized that the SP would show a cognitive deficit during the emotional transition of faces requiring fast emotional regulation. Second, we expected that there is altered neural activity in the SP compared to that in the NC in the prefrontal and cingulate cortex related to emotional regulation and cognitive control. Lastly, we hypothesized that BAS-Reward Responsiveness (BAS-RR) is correlated with the responses of happy faces related to the emotional reward in the SP.

\section{Results}

Demographics and clinical data. Table 1 summarizes the demographic and clinical characteristics of the two groups. The two groups did not differ in age, K-WAIS, and the main usage of smartphones, whereas the time of smartphone use per week, $t(50)=4.67, p<0.001$, the time of major smartphone use per week, $t(50)=3.47$, $p<0.005$, and Smartphone Addiction Proneness Scale (SAPS) scores, $t(50)=4.55, p<0.001$ were significantly different. The SP showed higher score on the BIS, $t(50)=3.6, p<0.001$ and BAS, $t(50)=5.38, p<0.001$, and 


\begin{tabular}{|c|c|c|c|c|c|}
\hline & \multicolumn{2}{|c|}{$\mathrm{SP}(\mathrm{n}=25)$} & \multicolumn{2}{|c|}{ NC $(n=27)$} & \multirow[b]{2}{*}{ t score } \\
\hline & mean & SD & mean & SD & \\
\hline Age & 27.76 & 5.97 & 28.93 & 6.39 & -0.61 \\
\hline K-WAIS & 111.84 & 10.59 & 113.04 & 10.53 & -0.41 \\
\hline Education duration (years) & 15.12 & 1.42 & 15.93 & 1.27 & $-2.16^{*}$ \\
\hline \multicolumn{6}{|l|}{ Gender } \\
\hline Male & $52.00 \%$ & $(\mathrm{n}=13)$ & $66.70 \%$ & $(\mathrm{n}=18)$ & $\mathrm{x}^{2}=1.160$ \\
\hline Female & $48.00 \%$ & $(\mathrm{n}=12)$ & $33.30 \%$ & $(\mathrm{n}=9)$ & \\
\hline Duration of smartphone use (year) & 4.60 & 1.29 & 4.85 & 1.63 & -0.61 \\
\hline Time for smartphone use per week (hours) & 44.96 & 26.05 & 15.7 & 18.84 & $4.67^{* * *}$ \\
\hline Time for major smartphone use per week (hours) & 24.79 & 21.15 & 9.8 & 7.17 & $3.47^{* *}$ \\
\hline \multicolumn{6}{|l|}{ Major usage of smartphone } \\
\hline Internet searching & \multicolumn{2}{|c|}{$12.00 \%$} & \multicolumn{2}{|c|}{$25.90 \%$} & $\mathrm{x}^{2}=5.063$ \\
\hline Social network service & \multicolumn{2}{|c|}{$64.00 \%$} & \multicolumn{2}{|c|}{$55.60 \%$} & \\
\hline Entertainment & \multicolumn{2}{|c|}{$12.00 \%$} & \multicolumn{2}{|c|}{$18.50 \%$} & \\
\hline etc. & \multicolumn{2}{|c|}{$12.00 \%$} & \multicolumn{2}{|c|}{$0 \%$} & \\
\hline SAPS & 41.72 & 4.77 & 20.41 & 4.55 & $16.48^{* * *}$ \\
\hline BIS scale & 20.52 & 3.04 & 17 & 3.6 & $3.8 * * *$ \\
\hline BAS scale & 36.76 & 4.02 & 31.59 & 5.38 & $3.9^{* * *}$ \\
\hline Reward responsiveness & 14.96 & 2.34 & 12.93 & 2.32 & $3.15^{* *}$ \\
\hline Drive & 10.48 & 1.5 & 10.11 & 2.55 & 0.63 \\
\hline Fun seeking & 11.32 & 1.65 & 8.56 & 2.21 & $5.08^{* * *}$ \\
\hline \multicolumn{6}{|l|}{ Economic status } \\
\hline Upper & \multicolumn{2}{|c|}{$12.00 \%$} & \multicolumn{2}{|c|}{$22.20 \%$} & $\mathrm{x}^{2}=2.408$ \\
\hline Upper-middle & \multicolumn{2}{|c|}{$12.00 \%$} & \multicolumn{2}{|c|}{$11.10 \%$} & \\
\hline Middle & \multicolumn{2}{|c|}{$28.00 \%$} & \multicolumn{2}{|c|}{$37.00 \%$} & \\
\hline Lower-middle & \multicolumn{2}{|c|}{$32.00 \%$} & \multicolumn{2}{|c|}{$22.20 \%$} & \\
\hline Lower & \multicolumn{2}{|c|}{$16.00 \%$} & \multicolumn{2}{|c|}{$7.40 \%$} & \\
\hline
\end{tabular}

Table 1. Demographic characteristics of the PSU and NC. Abbreviations: SP, Excessive smartphone use group; NC, Normal control group; SAPS, Smartphone Addiction Proneness Scale; BIS, Behavioral inhibition system; BAS, Behavioral activation system. $* p<0.05, * * p<0.005, * * * p<0.001$.

\begin{tabular}{|c|c|c|c|c|c|c|c|}
\hline & & & \multicolumn{2}{|c|}{ SP $(n=27)$} & \multicolumn{2}{|c|}{$\mathrm{NC}(\mathrm{n}=25)$} & \multirow[b]{2}{*}{ t score } \\
\hline & & & mean & SD & mean & SD & \\
\hline \multicolumn{8}{|c|}{ Error rate (\%) } \\
\hline \multirow{2}{*}{ Happy } & repetition & $\mathrm{HH}$ & 2.07 & 2.05 & 2.5 & 2.58 & -0.662 \\
\hline & transition & $\mathrm{AH}$ & 4.83 & 3.5 & 2.43 & 2.06 & $3.045^{*}$ \\
\hline \multirow{2}{*}{ Angry } & repetition & AA & 4.02 & 3.92 & 2.83 & 2.33 & 1.34 \\
\hline & transition & HA & 2.17 & 2.51 & 2.52 & 2.5 & -0.501 \\
\hline \multicolumn{8}{|c|}{ Reaction time (ms) } \\
\hline \multirow{2}{*}{ Happy } & repetition & $\mathrm{HH}$ & 708.61 & 71.23 & 695.91 & 67.05 & -0.662 \\
\hline & transition & $\mathrm{AH}$ & 763.7 & 73.59 & 727.68 & 73.36 & 1.767 \\
\hline \multirow{2}{*}{ Angry } & repetition & AA & 752.01 & 76.59 & 737.16 & 72.52 & 0.718 \\
\hline & transition & HA & 737.57 & 68.77 & 739.12 & 70.21 & -0.08 \\
\hline
\end{tabular}

Table 2. Behavioral responses. Abbreviations: SP, Excessive smartphone use group; NC, Normal control group; $\mathrm{HH}$, Happy face followed by happy face; AH, Angry face followed by happy face; AA, Angry face followed by angry face; HA, Happy face followed by angry face.

particularly the SP revealed higher score on the BAS-RR, $t(50)=2.32, p<0.005$ and BAS-Fun Seeking (BAS-FS), $t(50)=5.08, p<0.001$ compared to NC. Additionally, there was a significant difference in the education duration, $t(51)=2.16, p<0.05$, but the difference was around a year. According to gender distribution, there was no significant difference across groups.

Behavioral performance. As shown in Table 2 and Fig. 1, we conducted a repeated-measures ANOVA on the error rate with emotional valence of face (happy and angry), emotional status (repetition vs. transition), and group (SP and NC). For error rate, there was a 3-way interaction between the emotional valence, emotional 

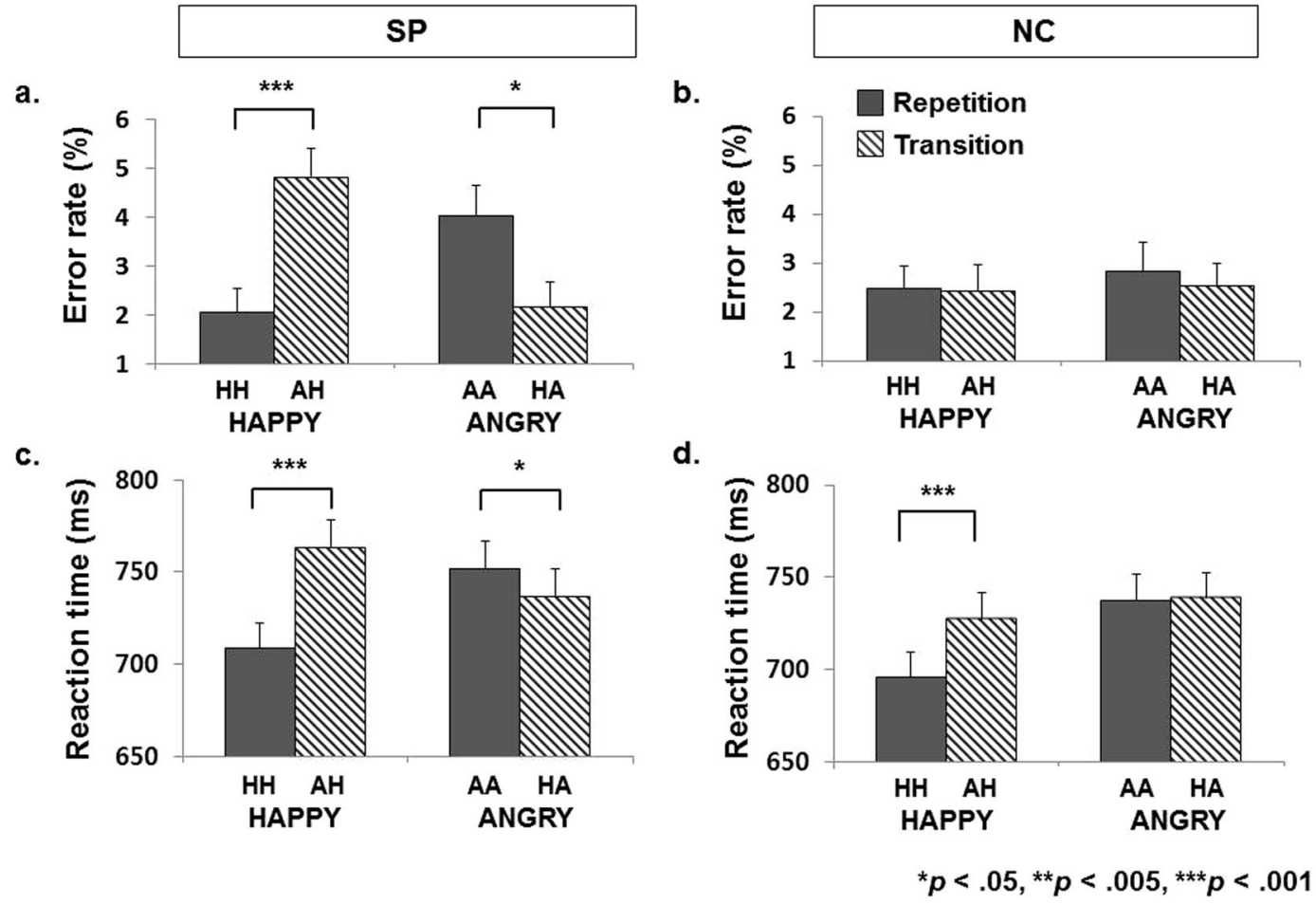

Figure 1. Behavioral responses of each group. In the SP, the error rate for $\mathrm{AH}$ was higher than that for the $\mathrm{HH}$, and the error rate for the AA was higher than that for the HA (a); however, there were no significant differences between conditions in the NC (b). The SP showed a higher error rate than the NC in the AH. The SP exhibited slower responses in the $\mathrm{AH}$ than in the $\mathrm{HH}$, and they also showed slower responses in the AA than the HA (c). The NC showed delayed responses in the AH trials compared to that in the $\mathrm{HH}$ trials, however, there were no significant differences between the AA and the HA in the NC (d).

status, and groups, $F(1,50)=11.52, \eta^{2}=0.91, p<0.001$. The ANOVA revealed significant interaction between the emotional valence and emotional status of the face, $F(1,50)=14.19, \eta^{2}=0.96, p<0.001$.

In the SP, the error rate for the $\mathrm{AH}$ was higher than that for the $\mathrm{HH}, t(24)=4.67, p<0.001$, and the error rate for the AA was higher than that for the HA, $t(24)=2.50, p<0.05$; however, there were no significant differences between conditions in the NC. In the group comparison, the SP showed a higher error rate than the NC in AH, $t(50)=2.04, p<0.005$.

For the reaction time, there were main effects for the emotional valence of the face, $F(1,50)=20.05, \eta^{2}=0.99$, $p<0.001$, and emotional status, $F(1,50)=33.32, \eta^{2}=1.00, p<0.001$. There were a 3 -way interaction among the two conditions and the groups, $F(1,50)=13.03, \eta^{2}=0.94, p<0.005$. There was a significant interaction in the reaction time between the emotional valence of the face and the groups, $F(1,50)=5.14, \eta^{2}=0.60, p<0.05$. There was a significant interaction between the emotional valence and emotional transition of the face, $F(1,50)=81.46$, $\eta^{2}=1.00, p<0.001$.

The SP exhibited slower responses in the $\mathrm{AH}$ than in the $\mathrm{HH}, t(24)=8.45, p<0.001$, and they also showed slower responses in the AA than the HA, $t(24)=2.77, p<0.05$. The NC showed delayed responses in the AH trials compared to that in the $\mathrm{HH}$ trials, $t(26)=5.96, p<0.001$, however, there were no significant differences between the AA and HA in the NC.

Regarding to correlation between the behavior response and effect of personality trait, BAS-RR score revealed a significant negative correlation with the error rate during the $\mathrm{HH}, r=-0.42, p<0.05$, in SP, however there was no significant correlation in NC (Fig. 2). The results were converted to equally probable $\mathrm{z}$-scores, comparing Fisher's $\mathrm{z}$-transformed correlation values across groups $(\mathrm{z}=1.65, p=0.049)$.

Functional MRI results. Group differences in emotional valence. The results from the emotional valence of the face condition analysis are presented in Table 3. In the happy face condition, the SP showed less activity in the left precentral gyrus (PG), left lingual gyrus (LG), right inferior temporal gyrus, left middle frontal gyrus (MFG), and left middle temporal gyrus than the NC. In the angry face condition, the SP exhibited less activity in the bilateral precentral gyri, left LG, bilateral middle temporal gyri, right superior parietal gyrus (SPG), left middle occipital gyrus, right dACC, left DLPFC, right supplementary motor area (SMA), right cuneus, right thalamus, left cerebellum, left superior occipital gyrus (SOG), and left MFG than the NC. However, the SP did not exhibit significantly more activity than the NC in either the happy or angry face condition.

Group differences in emotional status. The results from the analysis of the emotional status are presented in Table 4. The SP showed less activity in the right inferior temporal gyrus, left LG, and left PG than the NC with 


\section{a. DLPFC}
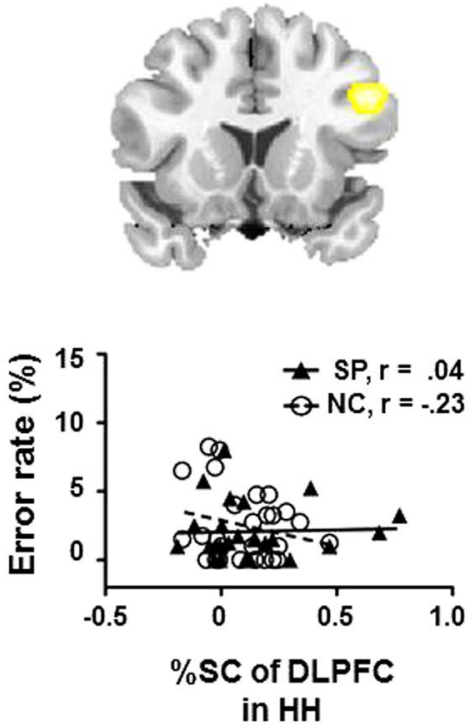

b. dACC

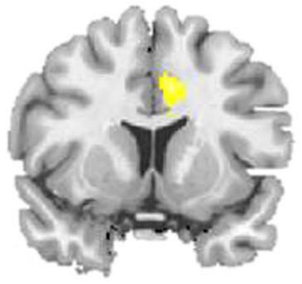

c. BAS-RR

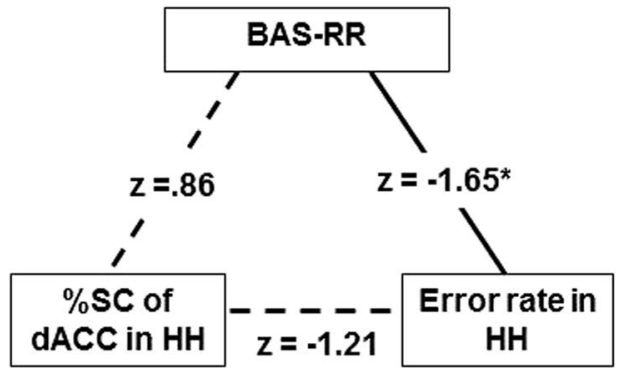

Figure 2. Correlations among neural activity of the ROIs, the error rate, and the BAS-RR scores. In the SP, the activation of the right DLPFC did not showed correlation with behavioral error (a), and the dACC exhibited negative correlation with the error rate under $\mathrm{HH}, r=-0.53, p<0.05$ in SP $(\mathbf{b})$. In the SP compared to NC, the error rate revealed a significant negative correlation with BAS-RR score during the $\mathrm{HH}, r=-0.42, p<0.05$ (c).

emotional repetition. The SP exhibited less activity in the bilateral precentral gyri, left LG, left STS, left SPG, left DLPFC, right interior temporal gyrus, left SMA, left inferior frontal gyrus, left supramarginal gyrus, left dorsal ACC, right TPJ, left inferior parietal gyrus, left SOG, right cuneus, and right superior frontal gyrus (SFG) with emotional transition. However, the SP did not exhibit significantly more activity than the NC with either emotional repetition or transition.

Regional differences between conditions within groups. The results from the analysis of the reginal differences between conditions for each group are presented in Table 5. The SP showed stronger activation in the right SFG, right LG, left middle occipital gyrus, right dorsal ACC, right MFG, right thalamus, right postcentral gyrus, right superior temporal gyrus, and left inferior parietal gyrus during $\mathrm{AH}$ than during $\mathrm{HH}$. Additionally, they revealed more activation of the right SFG, right DLPFC, left SPG, right inferior parietal gyrus, and right angular gyrus during AA than during HA. There were no significant differences in activity dependent on the condition in the SP. In contrast, the NC showed stronger activation in the left SPG, left SMA, left LG, and right SOG during AH than during $\mathrm{HH}$. There were no significant differences dependent on other conditions in the NC.

ROIs analysis. In the region of interest (ROI) analysis for exploring the activation differences of the DLPFC (Fig. 3), the main effect of the emotional status of the face was significant, $F(1,50)=4.75, \eta^{2}=0.57, p<0.05$, and the activation of DLPFC during emotional repetition was higher than that during emotional transition. The interaction between the emotional status and group was significant, $F(1,50)=8.90, \eta^{2}=0.83, p<0.005$. Also, the interaction between the emotional valence of the face and the emotional status was significant, $F(1,50)=48.35$, $\eta^{2}=1.00, p<0.001$.

In the multiple comparison, the right DLPFC in the SP showed stronger activity with emotional repetition than emotional transition, $t(24)=3.22, p<0.05$, while the difference was not significant in the NC. In the AH, the NC showed greater activity in the right DLPFC than in $\mathrm{HH}, t(26)=3.90, p<0.005$, but the SP did not show a significant difference in activity between the $\mathrm{AH}$ and $\mathrm{HH}$.

In terms of the activity in the right dACC (Fig. 3), the main effects of emotional valence of the face, $F(1,50)=8.37, \eta^{2}=0.81, p<0.005$, and emotional status, $F(1,50)=16.58, \eta^{2}=0.98, p<0.001$, were significant. The activation of dACC during happy face trials was higher than that during angry face trials, and the activation of dACC during emotional transition was higher than that during emotional repetition. The 3 -way interaction among the emotional valence, emotional status, and the groups was significant, $F(1,50)=6.43, \eta^{2}=0.70, p<0.05$. The interaction between the emotional valence of the face and the group was significant, $F(1,50)=6.15, \eta^{2}=0.11$, $p<0.05$. Additionally, the interaction between the emotional valence and emotional status of the face was significant, $F(1,50)=23.51, \eta^{2}=1.00, p<0.001$. In the right dACC, the SP showed greater activity in the happy than the angry faces, $t(24)=3.23, p<0.001$, but the NC did not show a significant difference. 


\begin{tabular}{|c|c|c|c|c|c|}
\hline \multirow[b]{2}{*}{ Region } & \multicolumn{3}{|c|}{ Coordinates } & \multirow[b]{2}{*}{ T-score } & \multirow[b]{2}{*}{ No. of Voxels } \\
\hline & $\mathbf{x}$ & $\mathbf{y}$ & $\mathbf{z}$ & & \\
\hline \multicolumn{6}{|l|}{ HAPPY face } \\
\hline \multicolumn{6}{|l|}{$S P>N C$} \\
\hline \multicolumn{6}{|l|}{ None } \\
\hline \multicolumn{6}{|l|}{$S P<N C$} \\
\hline L. Precentral gyrus & -52 & 2 & 40 & 10.12 & 342 \\
\hline L. Lingual gyrus & -14 & -80 & -2 & 8.93 & 319 \\
\hline R. Inferior temporal gyrus & 48 & -72 & -4 & 7.58 & 122 \\
\hline L. Middle frontal gyrus & -42 & 40 & 24 & 7.58 & 171 \\
\hline L. Middle temporal gyrus & -36 & -54 & 62 & 7.36 & 217 \\
\hline \multicolumn{6}{|l|}{ ANGRY face } \\
\hline \multicolumn{6}{|l|}{$S P>N C$} \\
\hline \multicolumn{6}{|l|}{ None } \\
\hline \multicolumn{6}{|l|}{$S P<N C$} \\
\hline \multirow[t]{2}{*}{ B. Precentral gyrus } & -52 & 4 & 46 & 10.03 & 366 \\
\hline & 48 & 6 & 52 & 9.35 & 301 \\
\hline L. Lingual gyrus & -18 & -80 & -4 & 9.47 & 761 \\
\hline \multirow[t]{2}{*}{ B. Middle temporal gyrus } & 42 & -68 & -2 & 9.03 & 205 \\
\hline & -56 & -52 & 10 & 8.66 & 807 \\
\hline R. Superior parietal gyrus & 38 & -52 & 62 & 8.74 & 694 \\
\hline L. Middle occipital gyrus & -38 & -88 & -2 & 9.2 & 365 \\
\hline R. dorsal ACC & 4 & 12 & 32 & 8.58 & 338 \\
\hline L. DLPFC & -42 & 38 & 20 & 8.43 & 190 \\
\hline R. SMA & 2 & -4 & 66 & 7.63 & 402 \\
\hline R. Cuneus & 6 & -88 & 14 & 7.84 & 210 \\
\hline R. Thalamus & 18 & -10 & 6 & 7.73 & 372 \\
\hline L. Cerebellum & -20 & -60 & -14 & 7.67 & 118 \\
\hline L. Superior occipital gyrus & -24 & -90 & 30 & 7.46 & 271 \\
\hline L. Middle frontal gyrus & -24 & 50 & 34 & 7.4 & 239 \\
\hline
\end{tabular}

Table 3. Group differences of brain regions showing significant activation in each emotional valence. Clusters with peak-level and FWE-corrected $\mathrm{p}<0.001$ and more than 100 voxels are reported. Abbreviations: L., Left; R., Right; B., Bilateral; ACC, Anterior cingulate cortex; DLPFC, Dorsolateral prefrontal cortex; SMA, Supplementary motor area; FWE, family wise error.

In the SP, multiple comparisons revealed that the activation of the right $\mathrm{AACC}$ exhibited negative correlation with the error rate under $\mathrm{HH}, r=-0.53, p<0.05$ (Fig. 2), however, right DLPFC did not show a significant correlation between the BAS score and regional activations.

\section{Discussion}

The aim of this study was to identify the behavioral differences between the SP and NC, and the altered brain activation of the prefrontal and cingulate cortex associated with cognitive control in SP compared to that of $\mathrm{NC}$ during facial emotion processing. Additionally, we identified the correlations between the BAS-RR activity, behavioral, and neural response during facial emotion processing related to emotional reward. We hypothesized that, based on the vulnerability of the excessive smartphone user in social interaction, SP would reveal deficit of cognitive control in behavioral and neural responses during facial emotional processing. In addition, we predicted that reward sensitivity in the SP would influence on cognitive processing of social reward cue.

In this study, the SP showed higher error rate induced by failure of cognitive control during presentations of angry face in the previous trial, whereas the NC did not show such a difference. These results indicated that the SP suffered difficulty on cognitive control caused by emotional evaluation when they are exposed to negative emotional expression. In particular, the SP showed a higher error rate under the emotional transition preceded by a negative emotional face, compared to the NC. These behavioral findings would indicate that the previous exposure to a negative emotion influenced the cognitive control on the current emotional transition trial in the SP.

In the neural response, the SP showed decreased activation in the dACC and DLPFC related to cognitive control of facial emotion compared to NC under angry face and emotional transition. These results associated with previous studies which reported dysfunction of frontolimbic region related to cognitive control in Internet gaming disorder ${ }^{59}$. The previous studies have reported that cognitive reappraisal of negative emotion activates the dACC and PFC systems that support the selection and application of reappraisal strategies and modulate activity in appraisal systems suitable for the goal of reappraisal ${ }^{53,60-65}$. In the results of meta-analysis, it has been reported that emotional interference during cognitive conflict induced neural activities in the DLPFC and $\mathrm{dACC}^{66}$. Therefore, decreased activity of both the dACC and DLPFC in the SP suggests that the cognitive 


\begin{tabular}{|c|c|c|c|c|c|}
\hline \multirow[b]{2}{*}{ Region } & \multicolumn{3}{|c|}{ Coordinates } & \multirow[b]{2}{*}{ T-score } & \multirow[b]{2}{*}{ No. of Voxels } \\
\hline & $\mathbf{x}$ & $\mathbf{y}$ & $\mathbf{z}$ & & \\
\hline \multicolumn{6}{|l|}{ Emotional repetition } \\
\hline \multicolumn{6}{|l|}{$S P>N C$} \\
\hline \multicolumn{6}{|l|}{ None } \\
\hline \multicolumn{6}{|l|}{$S P<N C$} \\
\hline R. Inferior temporal gyrus & 46 & -72 & -4 & 8.94 & 167 \\
\hline L. Lingual gyrus & -16 & -80 & -2 & 8.61 & 374 \\
\hline L. Precentral gyrus & -52 & 4 & 46 & 8.21 & 147 \\
\hline \multicolumn{6}{|l|}{ Emotional transition } \\
\hline \multicolumn{6}{|l|}{$S P>N C$} \\
\hline \multicolumn{6}{|l|}{ None } \\
\hline \multicolumn{6}{|l|}{$S P<N C$} \\
\hline \multirow[t]{2}{*}{ B. Precentral gyrus } & -50 & 2 & 42 & 12.98 & 811 \\
\hline & 48 & 8 & 50 & 9.36 & 257 \\
\hline L. Lingual gyrus & -16 & -82 & -4 & 10.62 & 698 \\
\hline L. Superior temporal sulcus & -50 & -52 & 6 & 9.68 & 2108 \\
\hline L. Superior parietal gyrus & -30 & -66 & 60 & 9.34 & 270 \\
\hline L. DLPFC & -44 & 40 & 22 & 9.44 & 749 \\
\hline R. Inferior temporal gyrus & 42 & -66 & -2 & 8.97 & 149 \\
\hline L. Supplementary motor area & -6 & 0 & 68 & 8.47 & 482 \\
\hline L. Inferior frontal gyrus & -44 & 24 & 2 & 8.19 & 137 \\
\hline L. Supramarginal gyrus & -54 & -50 & 30 & 8.6 & 214 \\
\hline L. dorsal ACC & 0 & 14 & 32 & 7.89 & 380 \\
\hline R. Tempro-parietal junction & 62 & -56 & 20 & 7.84 & 173 \\
\hline L. Inferior parietal gyrus & -44 & -46 & 56 & 7.46 & 566 \\
\hline L. Superior occipital gyrus & -24 & -90 & 30 & 7.24 & 109 \\
\hline R. Cuneus & 4 & -90 & 16 & 6.89 & 101 \\
\hline R. Superior frontal gyrus & 4 & 34 & 46 & 6.65 & 101 \\
\hline
\end{tabular}

Table 4. Group differences of brain regions showing significant activation in emotional status. Clusters with peak-level and FWE-corrected $\mathrm{p}<0.001$ and more than 100 voxels are reported. Abbreviations: L., Left; R., Right; B., Bilateral; STS, Superior temporal sulcus; ACC, Anterior cingulate cortex; DLPFC, Dorsolateral prefrontal cortex; SMA, Supplementary motor area; TPJ, Tempro-parietal junction; FWE, family wise error.

control of negative emotion and emotional transition has been altered compared to that in the NC. Consistent with neural activities, the SP reported higher error in emotional transition after angry face comparted to NC. Therefore, excessive smartphone user has a harmful effect on cognitive control during emotional face processing, and this impairment might be influenced on emotional processing related to social interaction. Additionally, the SP revealed neural deactivation of the STS and TPJ compared to the NC. According to a previous study related to facial information, the activation of the STS is associated with processing and reacting to the emotional state of another person ${ }^{41}$. Additionally, it has been known that the right TPJ is selectively recruited for the attribution of mental states when receiving socially relevant stimuli ${ }^{67,68}$ and is more responsive to mentalizing than physical judgments ${ }^{69}$. Therefore, this evidence suggests that activation of the STS and TPJ during emotional transition reflects the social cognitive effort to make a rapid emotional judgment, and the SP showed a lower neural response towards emotional information involved in social context than the NC.

In the ROIs comparison, we found that NC showed higher activation of DLPFC during presentations of angry face in previous trial than during presentations of happy face in the previous trial, while the SP did not show significant difference of neural activation between the previous emotional valences under current happy face. Cognitive reappraisal has been known to enhance the signal in the DLPFC regions in cognitive regulation of negative emotion ${ }^{70}$. In a previous study on emotional distracters, normal control participants were able to recruit the DLPFC; however, depressed individuals showed an exaggerated amygdala response to such distracters and a failure to recruit the DLPFC ${ }^{71}$. In this study, the activation of DLPFC during emotional repetition was higher than that during emotional transition. The effect of repeated emotion revealed only in the angry face, not in the happy face. In particular, SP showed strong activation in DLPFC during repeated angry face compared to non-repeated angry face. In the previous study related to emotional processing, the repeated negative stimuli induced significant activation in the DLPFC, and functional connectivity between the DLPFC and other regions ${ }^{72}$. The activation of DLPFC can be regarded as a cognitive effort in other to process repeated angry faces. In previous studies, the right lateral prefrontal regions have been shown to be activated under interference conditions ${ }^{73,74}$, and the activation of right DLPFC region negatively correlated with sensitivity of interference ${ }^{54}$. Despite the higher DLPFC activation, the SP showed more behavioral errors during the repeated angry face than non-repeated angry 


\begin{tabular}{|l|c|c|c|c|c|c|c|}
\hline \multirow{2}{*}{ Region } & \multicolumn{9}{|c|}{ Coordinates } & \multirow{2}{*}{} & \multirow{2}{*}{} \\
\cline { 2 - 5 } & $\mathbf{x}$ & $\mathbf{y}$ & $\mathbf{z}$ & T-score & No. of Voxels & Condition \\
\hline SP & 28 & -4 & 62 & 6.85 & 458 & $\mathrm{HH}<\mathrm{AH}$ \\
\hline R. Superior frontal gyrus & 6 & -90 & 2 & 6.33 & 659 & $\mathrm{HH}<\mathrm{AH}$ \\
\hline R. Lingual gyrus & -30 & -68 & 32 & 5.82 & 72 & $\mathrm{HH}<\mathrm{AH}$ \\
\hline L. Middle occipital gyrus & 6 & 10 & 38 & 5.8 & 136 & $\mathrm{HH}<\mathrm{AH}$ \\
\hline R. dorsal ACC* & 34 & 48 & 22 & 5.71 & 141 & $\mathrm{HH}<\mathrm{AH}$ \\
\hline R. Middle frontal gyrus & 14 & -20 & 12 & 5.56 & 77 & $\mathrm{HH}<\mathrm{AH}$ \\
\hline R. Thalamus & 30 & -42 & 66 & 5.42 & 503 & $\mathrm{HH}<\mathrm{AH}$ \\
\hline R. Postcentral gyrus & 46 & -22 & 12 & 5.42 & 148 & $\mathrm{HH}<\mathrm{AH}$ \\
\hline R. Superior temporal gyrus & -34 & -52 & 52 & 5.36 & 102 & $\mathrm{HH}<\mathrm{AH}$ \\
\hline L. Inferior parietal gyrus & 12 & 36 & 38 & 6.88 & 490 & $\mathrm{AA}>\mathrm{HA}$ \\
\hline R. Superior frontal gyrus & 48 & 16 & 32 & 6.47 & 333 & $\mathrm{AA}>\mathrm{HA}$ \\
\hline R. DLPFC & -38 & -68 & 54 & 6.01 & 291 & $\mathrm{AA}>\mathrm{HA}$ \\
\hline L. Superior parietal gyrus & -38 & -50 & 36 & 5.79 & 190 & $\mathrm{AA}>\mathrm{HA}$ \\
\hline R. Inferior parietal gyrus & 50 & 38 & -74 & 42 & 5.77 & 251 & $\mathrm{AA}>\mathrm{HA}$ \\
\hline R. Angular gyrus & & & & & & \\
\hline NC & -28 & -60 & 44 & 6.31 & 517 & $\mathrm{HH}<\mathrm{AH}$ \\
\hline L. Superior parietal gyrus & -4 & 0 & 66 & 6.23 & 181 & $\mathrm{HH}<\mathrm{AH}$ \\
\hline L. SMA & -8 & -90 & -6 & 6.2 & 400 & $\mathrm{HH}<\mathrm{AH}$ \\
\hline L. Lingual gyrus & 18 & -96 & 4 & 5.37 & 76 & $\mathrm{HH}<\mathrm{AH}$ \\
\hline R. Superior occipital gyrus & & & & &
\end{tabular}

Table 5. Brain regions of each group showing significant activation in conditions. Clusters with peak-level and FWE-corrected $\mathrm{p}<0.05$ and more than 100 voxels are reported. Abbreviations: L., Left; R., Right; B., Bilateral; ACC, Anterior cingulate cortex; DLPFC, Dorsolateral prefrontal cortex; SMA, Supplementary motor area; FWE, family wise error; *Region of Interest.

face. Therefore, it would imply that the neural activity related emotional regulation fails to control the behavioral performance in excessive smartphone user.

The SP also showed less activation of the dACC, which is related to conflict monitoring, during presentations of angry faces than the NC and compared to happy faces within the SP. The dACC has been known to be associated with detecting cognitive conflict ${ }^{47,57,75,76}$ and signaling the need for greater allocation of attention for the purpose of resolving conflict ${ }^{54}$. In the previous study related to altered brain structure of mobile phone dependence (MPD), MPD individuals had decreased gray matter volume relative to controls, and they showed decreased white matter integrity of bilateral hippocampal cingulum bundle fibers ${ }^{9}$. Therefore, it can be inferred that the SP have a deficit in cognitive monitoring during the presence of negative emotional faces compared to $\mathrm{NC}$ and, as this result, the SP revealed higher error rate under angry face followed by happy face compared to NC. Additionally, the SP showed a higher error with less neural activity in the dACC related to cognitive monitoring during repeated happy face, while there was no significant correlation between error rate and activity in the DLPFC related to cognitive conflict resolution. In other words, it imply that the SP showed individual differences according to cognitive monitoring during repeated happy face related to emotional reward.

In this study, correlations between the BAS-RR level, behavioral and neural response of facial emotion were shown to depend on the group. In the correlation results, high BAS-RR individuals in the SP exhibited low error rate during repeated happy face. In particular, the correlation between the BAS-RR and error rate in repeated happy face showed a significant difference between the SP and NC. These results indicate that sensitivity of reward more influence behavioral performance during repeated positive facial expression in the SP compared to NC. Therefore, it can be supposed that high BAS-RR individuals in the SP are sensitive to emotional reward such as happy face, and they might use social network service in order to gain positive responses. This is related to a previous finding that people who have a negative social identity tend to use SNSs more in order to compensate for this ${ }^{19}$.

Finally, a number of important limitations need to be considered. First, the participants did not evaluate the emotional valence and arousal of each face in this study. Second, the main usages of smartphone were heterogeneous among the participants. A future study with more focus on problematic social network service use through smartphones is therefore suggested. Third, the gender differences in excessive smartphone use group were not considered. In subsequent study, it is necessary to identify differences in facial emotional discrimination according to gender differences in the SP using the same gender distribution. Additionally, we suggest that the functional connectivity of fronto-cingulate regions in SP are investigated in social cognitive contexts in future studies.

In summary, we showed that the SP exhibited different behavioral responses and functional alterations compared to the NC during emotional processing of faces. The SP revealed a cognitive deficit during the emotional transition preceded by a negative emotional face, compared to NC. In the neural activity, the SP showed a neural deactivation of prefrontal and cingulate cortex related to conflict detection and cognitive control compared to that of the NC during exposure to angry faces and emotional transition. The behavioral performance in the SP 
a. $\operatorname{DLPFC}(x=48, y=16, z=30)$
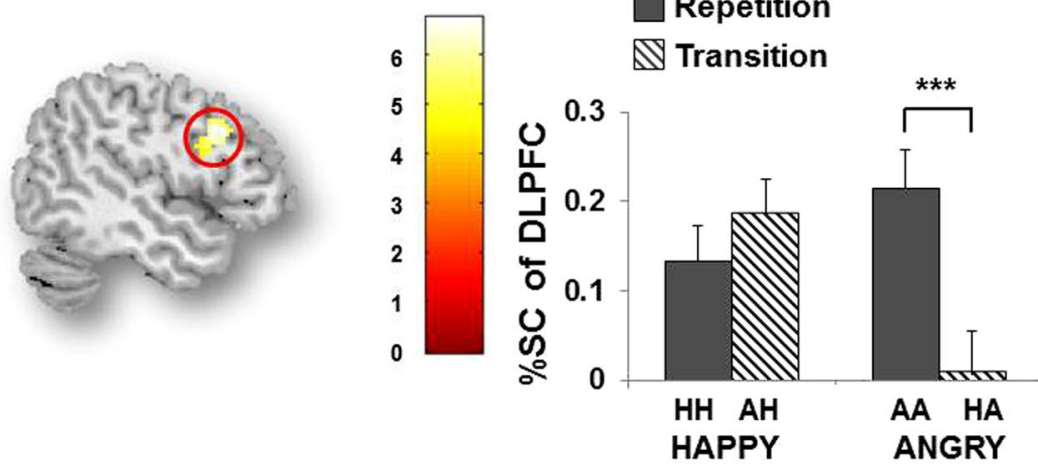

b.

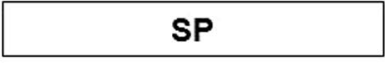

Repetition Transition

c. $\operatorname{dACC}(x=6, y=12, z=38)$

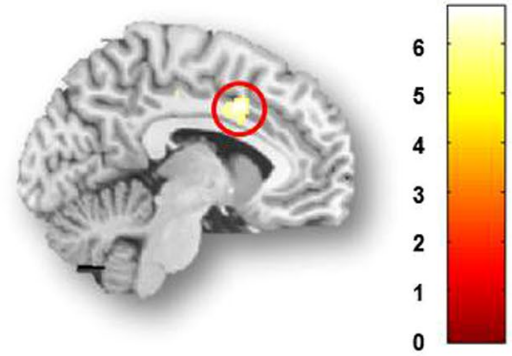

d.

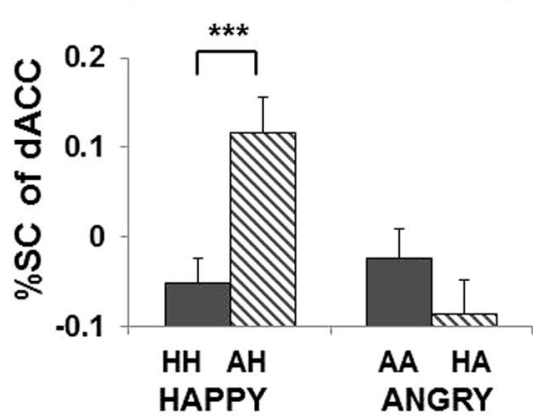

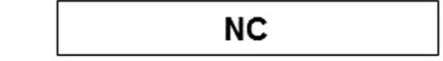

${ }^{*} p<.05,{ }^{* *} p<.005,{ }^{* * *} p<.001$
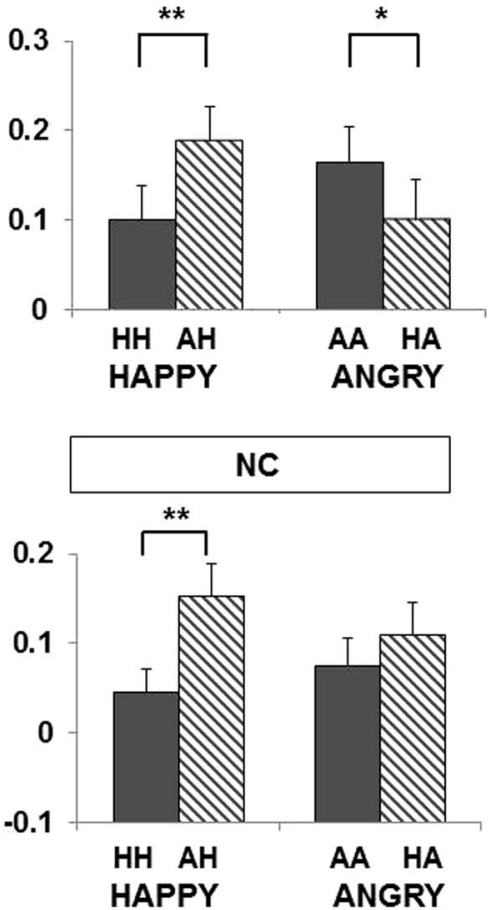

Figure 3. Neural activity in the DLPFC and dACC of each group. The right DLPFC extracted from the contrast between $\mathrm{HH}$ and $\mathrm{AH}$ in SP (a), and the right DLPFC in the SP showed stronger activity with emotional repetition than emotional transition, while the difference was not significant in the NC. Additionally, the NC showed greater activity in $\mathrm{AH}$ than in $\mathrm{HH}$, while the difference was not significant in the SP (b). The right dACC extracted from the contrast between AA and HA in SP (c). In the right dACC, the SP showed greater activity in the happy than the angry faces, but the NC did not show a significant difference. Additionally, the SP revealed deactivation of the AACC in the $\mathrm{HH}, \mathrm{AA}$, and HA trials compared to observed in the NC (d).

correlated with the activity of dACC related to cognitive monitoring during repeated happy face associated with emotional reward. Lastly, we found BAS-RR level was correlated with behavioral responses during repeated happy faces related to emotional reward in SP compared to NC. These findings may help us to understand altered neural responses associated with cognitive control during facial emotional processing, and could provide important implications for the effect of personality traits related to emotional reward in excessive smartphone use.

\section{Methods}

Participants. This study was conducted for adult men and women aged 19-35 through online recruiting. A total of 728 adults participated in the online survey on smartphone usage. Twenty-six adults with SP (14 male and 12 female) and $30 \mathrm{NC}$ (18 male and 12 female) were recruited for the fMRI study, and all participants underwent the Mini-International Neuropsychiatric Interview by a clinician to screen out participants with a current psychiatric diagnosis. One participant was excluded because of depressive disorder, and the data from three participants were excluded because of severe head motion during the analysis; thus, the data from twenty-five adults with problematic smartphone use (13 male and 12 female, $27.76 \pm 5.97$ years) and twenty-seven NC (18 male and 9 female, $28.93 \pm 6.39$ years) were considered in this study (Table 1). Exclusion criteria included past or current major medical disorders (e.g., diabetes mellitus), neurological disorders (e.g., seizure disorders, head injury) or psychiatric disorders (e.g., major depressive disorder, anxiety disorders). All participants had normal or corrected-to-normal vision and were right-handed assessed by the Edinburgh handedness inventory ${ }^{77}$. The purpose and procedure of this study were explained to the participants. Each participant provided written informed consent, and this study was approved by the Institutional Review Board of Seoul St. Mary's Hospital. All experiments were performed in accordance with relevant guidelines and regulations.

Questionnaires. SAPS. Excessive smartphone use was estimated using SAPS developed by the Korean National Information Society Agency in 2011 and the reliability test of the scale yielded a Cronbach's alpha of $0.814^{78}$. The SAPS is a self-report scale and includes fifteen items, and the responses are scored on a four-point Likert scale (1: Not at all to 4: Always). The SAPS has four subscales: disturbance of adaptive functions, virtual life orientation, withdrawal, and tolerance, and participants were classified as SP if their total score exceeded 44, or 
if their subscales scores exceeded 15, 13, and 13 for disturbance of adaptive function, withdrawal, and tolerance, respectively.

BIS/BAS. BIS and BAS are general motivation systems that underlie behavior and affect $^{28}$. The BIS responds to cues associated with punishment; the BAS responds to those associated with reward. The BIS and BAS questionnaire scales assess BIS (7 items) and three subdomains of BAS-D (4 items), BAS-FS(4 items), and BAS-RR (5 items $)^{31}$. Responses used a 4-point scale (1: strongly disagree, 4: strongly agree). Items on the BIS scale assess sensitivity to the mechanism controlling aversive motivation. Items in the BAS-RR subscale assess positive responses to anticipated rewards. Items in the BAS-D subscale assess persistent pursuit of desired appetitive goals. Items in the BAS-FS subscale assess desire for new rewards and willingness to spontaneously approach potentially rewarding events ${ }^{14}$.

Facial emotion discrimination task. Participants performed a facial emotion discrimination task using Korean emotional faces, which were selected from the Korean Facial Expressions of Emotion ${ }^{79}$. To maintain the participants' attention, the stimulus material for each trial consisted of a positive or negative emotional face on the left or right side and a fixation cross at the center of the gray background. Half of the participants were asked to press a button with their left or right index finger in response to a positive or negative feeling produced by the picture, respectively, regardless of the picture's location. The other half of the participants were assigned to respond in the opposite manner as a counterbalance. The trials consisted of four different stimuli according to emotional valence (happy vs. angry) and emotional status (repetition vs. transition) of face. The task sequence was separated into two sessions and was composed of a rapid event-related design in which the duration of each trial was 1,500 $\mathrm{ms}$ and the inter-trial intervals were varied from 500 to $4,500 \mathrm{~ms}$. Each session started with a 12-s dummy scan with six practice trials and included 160 events consisting of 40 repeated happy face trials, 40 non-repeated happy face trials, 40 repeated angry face trials, and 40 non-repeated angry face trials, and thus took a total duration of $7 \mathrm{~min} 32 \mathrm{~s}$.

Image acquisition. Functional and structural MRI data were acquired using a 3T MRI system (Siemens, MAGNETOM Verio, Erlangen, Germany) equipped with a 16-channel head coil. Participants' heads were cushioned with attached earmuffs. The functional images were obtained using a T2*-weighted gradient echo-planar imaging sequence (31 slices of $3.5-\mathrm{mm}$ thickness and no gaps, repetition time $[\mathrm{TR}]=2,000 \mathrm{~ms}$, echo time $[\mathrm{TE}]=30 \mathrm{~ms}$, flip angle $=90^{\circ}$, image matrix $=124 \times 124$, field of view $=220 \mathrm{~mm}$ ) with an in-plane resolution of $1.719 \mathrm{~mm} \times 1.719 \mathrm{~mm}$. Structural images with a resolution of $0.859 \mathrm{~mm} \times 0.859 \mathrm{~mm} \times 1.2 \mathrm{~mm}$ were acquired using a 3D T1-weighted gradient echo sequence ( 170 slices, $\mathrm{TR}=9.692 \mathrm{~ms}, \mathrm{TE}=4.59 \mathrm{~ms}$, image matrix $=224 \times 224)$.

Data analysis. Behavioral data. The behavioral data were analyzed according to the emotional valence of the face, the stimuli exposure, and the group. The three variables of interest were the emotional valence of the face (happy vs. angry), emotional status (repetition vs. transition), and group (SP vs. NC). The task performances, measured by accuracy and reaction time, were analyzed by a repeated measures analysis of variance (ANOVA) to assess the main effects of the three factors and their interactions using IBM SPSS Statistics for Windows, Version 20.0 (IBM SPSS Inc., Armonk, NY). Subsequent paired t-tests for post hoc analyses were performed to test the significance between the different conditions and groups.

Image data. Image preprocessing and statistical analysis were performed with Statistical Parametric Mapping software (SPM8; Wellcome Department of Cognitive Neurology, London, UK). After discarding the first six images from the dummy scan at each session, the remaining 220 images were used for further preprocessing. Differences in the slice acquisition time of the interleaved sequence were corrected, and realignment was performed to correct the artifact created by head motion. The corrected images were coregistered on the T1-weighted image of the same participant. The T1-weighted images were normalized to the standard T1 template, and the resulting transformation matrices were applied to the coregistered functional images. Functional data were smoothed with a Gaussian kernel of 8-mm full-width at half-maximum.

Preprocessed data were analyzed using a general linear model. Experimental trials were modeled separately using a canonical hemodynamic response function for individual data. Multiple linear regression, as implemented in SPM8 using a least-squares approach, was used to obtain the parameter estimates ${ }^{80}$. These estimates were then analyzed by testing specific contrasts using the participant as a random factor. According to the emotional valence and emotional status of the face, all trials were classified as $\mathrm{HH}, \mathrm{AH}, \mathrm{AA}$, and $\mathrm{HA}$ trials. Images of the parameter estimates for each condition were created in the primary analysis, during which individual realignment parameters were entered as regressors to control for movement-related variance.

For the secondary analysis, the parameters for the four conditions, which were estimated in the primary analysis, and group condition were entered into the flexible factorial model, in which contrast maps were compared for group differences. The results were measured with group differences in relation to the emotional valence (happy and angry) and emotional status (repetition vs. transition) of the face. Significant results were determined by family-wise error (FEW) corrected p values of less than 0.001 and more than 100 voxels preferentially.

Post hoc tests for interactions and correlation analysis were performed on the a priori regions of interest (ROIs), which were defined as significant clusters within fronto-cingulate regions including the dACC $[6,10,38]$ and DLPFC $[48,16,32]$ related to cognitive control for emotional faces in group. The \% BOLD signal changes in the ROIs were extracted in each condition using MarsBaR version 0.41 (http://marsbar.sourceforge.net), and the differences for the ROIs were analyzed using repeated measures ANOVA. The correlations between ROIs and 
behavioral error rate were calculated using Pearson correlation analyses in each condition and groups, and the p-values were adjusted by Benjamin-Hochberg FDR for multiple comparisons. Also, the statistical difference in regional correlation results between groups was computed after application of Fisher's r-to-z transform.

\section{References}

1. Billieux, J., Maurage, P., Lopez-Fernandez, O., Kuss, D. J. \& Griffiths, M. D. Can Disordered Mobile Phone Use Be Considered a Behavioral Addiction? An Update on Current Evidence and a Comprehensive Model for Future Research. Current Addiction Reports 2, 156-162, doi:10.1007/s40429-015-0054-y (2015).

2. Billieux, J. et al. Is Dysfunctional Use of the Mobile Phone a Behavioural Addiction? Confronting Symptom-Based Versus ProcessBased Approaches. Clinical psychology \& psychotherapy 22, 460-468, doi:10.1002/cpp.1910 (2015).

3. Lopez-Fernandez, O. Short version of the Smartphone Addiction Scale adapted to Spanish and French: Towards a cross-cultural research in problematic mobile phone use. Addictive behaviors 64, 275-280, doi:10.1016/j.addbeh.2015.11.013 (2017).

4. Bianchi, A. \& Phillips, J. G. Psychological predictors of problem mobile phone use. Cyberpsychology \& behavior: the impact of the Internet, multimedia and virtual reality on behavior and society 8, 39-51, doi:10.1089/cpb.2005.8.39 (2005).

5. Butt, S. \& Phillips, J. G. Personality and self reported mobile phone use. Computers in Human Behavior 24, 346-360, doi:10.1016/j. chb.2007.01.019 (2008).

6. Augner, C. \& Hacker, G. W. Associations between problematic mobile phone use and psychological parameters in young adults. International journal of public health 57, 437-441, doi:10.1007/s00038-011-0234-z (2012).

7. Ehrenberg, A., Juckes, S., White, K. M. \& Walsh, S. P. Personality and self-esteem as predictors of young people's technology use. Cyberpsychology \& behavior: the impact of the Internet, multimedia and virtual reality on behavior and society 11, 739-741, doi:10.1089/cpb.2008.0030 (2008)

8. Ha, J. H., Chin, B., Park, D. H., Ryu, S. H. \& Yu, J. Characteristics of excessive cellular phone use in Korean adolescents. Cyberpsychology \& behavior: the impact of the Internet, multimedia and virtual reality on behavior and society 11, 783-784, doi:10.1089/cpb.2008.0096 (2008).

9. Wang, Y. et al. Altered Gray Matter Volume and White Matter Integrity in College Students with Mobile Phone Dependence. Frontiers in psychology 7, 597, doi:10.3389/fpsyg.2016.00597 (2016).

10. Goossens, L. et al. The genetics of loneliness: linking evolutionary theory to genome-wide genetics, epigenetics, and social science. Perspectives on psychological science: a journal of the Association for Psychological Science 10, 213-226, doi:10.1177/1745691614564878 (2015).

11. Ye, Y. \& Lin, L. Examining relations between locus of control, loneliness, subjective well-being, and preference for online social interaction. Psychological reports 116, 164-175, doi:10.2466/07.09.PR0.116k14w3 (2015).

12. Reid, D. J. \& Reid, F. J. Text or talk? Social anxiety, loneliness, and divergent preferences for cell phone use. Cyberpsychology of behavior: the impact of the Internet, multimedia and virtual reality on behavior and society 10, 424-435, doi:10.1089/cpb.2006.9936 (2007).

13. Lin, Y. H. et al. Development and validation of the Smartphone Addiction Inventory (SPAI). PloS one 9, e98312, doi:10.1371/journal. pone.0098312 (2014).

14. Kim, Y. et al. Personality Factors Predicting Smartphone Addiction Predisposition: Behavioral Inhibition and Activation Systems, Impulsivity, and Self-Control. PloS one 11, e0159788, doi:10.1371/journal.pone.0159788 (2016).

15. Takao, M., Takahashi, S. \& Kitamura, M. Addictive personality and problematic mobile phone use. Cyberpsychology \& behavior: the impact of the Internet, multimedia and virtual reality on behavior and society 12, 501-507, doi:10.1089/cpb.2009.0022 (2009).

16. Beard, K. W. \& Wolf, E. M. Modification in the proposed diagnostic criteria for Internet addiction. Cyberpsychology \& behavior: the impact of the Internet, multimedia and virtual reality on behavior and society 4, 377-383 (2001).

17. Kwon, J. H., Chung, C. S. \& Lee, J. The effects of escape from self and interpersonal relationship on the pathological use of Internet games. Community mental health journal 47, 113-121, doi:10.1007/s10597-009-9236-1 (2011).

18. Nyland, R., Marvez, R. \& Beck, J. Social networking or social isolation? In Proceedings of the Midwinter Conference of Association for Education in Journalism and Mass Communication 23-24 (2007).

19. Barker, V. Older adolescents' motivations for social network site use: the influence of gender, group identity, and collective selfesteem. Cyberpsychology \& behavior: the impact of the Internet, multimedia and virtual reality on behavior and society 12, 209-213, doi:10.1089/cpb.2008.0228 (2009).

20. Kuss, D. J. \& Griffiths, M. D. Online social networking and addiction-a review of the psychological literature. International journal of environmental research and public health 8, 3528-3552, doi:10.3390/ijerph8093528 (2011).

21. Volkow, N. D., Baler, R. D. \& Goldstein, R. Z. Addiction: pulling at the neural threads of social behaviors. Neuron 69, 599-602, doi:10.1016/j.neuron.2011.01.027 (2011).

22. Wang, E. S. \& Wang, M. C. Social support and social interaction ties on internet addiction: integrating online and offline contexts. Cyberpsychology, behavior and social networking 16, 843-849, doi:10.1089/cyber.2012.0557 (2013).

23. Choi, S. W. et al. Comparison of risk and protective factors associated with smartphone addiction and Internet addiction. Journal of behavioral addictions 4, 308-314, doi:10.1556/2006.4.2015.043 (2015).

24. Carver, C. S. \& White, T. L. Behavioral inhibition, behavioral activation, and affective responses to impending reward and punishment: The BAI/BAS Scales. Journal of Personality and Social Psychology 67, 319-333 (1994).

25. Carver, C. S. \& Scheier, M. F. Origins and functions of positive and negative affect: A control-process view. Psychological Review 97, 19-35 (1990).

26. Gray, J. A. Perspectives on anxiety and impulsivity: A commentary. Journal of Research in Personality 21, 493-509 (1987).

27. Carver, C. S. Negative affects deriving from the behavioral approach system. Emotion 4, 3-22, doi:10.1037/1528-3542.4.1.3 (2004).

28. Gray, A. C., McLeod, J. D. \& Clothier, R. H. A review of in vitro modelling approaches to the identification and modulation of squamous metaplasia in the human tracheobronchial epithelium. Alternatives to laboratory animals: ATLA 35, 493-504 (2007).

29. Franken, I. H., Muris, P. \& Georgieva, I. Gray's model of personality and addiction. Addictive behaviors 31, 399-403, doi:10.1016/j. addbeh.2005.05.022 (2006).

30. McNaughton, N. \& Gray, J. A. Anxiolytic action on the behavioural inhibition system implies multiple types of arousal contribute to anxiety. Journal of affective disorders 61, 161-176 (2000).

31. Carver, C. S. \& Scheier, M. F. Situational coping and coping dispositions in a stressful transaction. Journal of personality and social psychology 66, 184-195 (1994).

32. Chou, W. J., Liu, T. L., Yang, P., Yen, C. F. \& Hu, H. F. Multi-dimensional correlates of Internet addiction symptoms in adolescents with attention-deficit/hyperactivity disorder. Psychiatry research 225, 122-128, doi:10.1016/j.psychres.2014.11.003 (2015).

33. Lam, L. T. Risk factors of Internet addiction and the health effect of internet addiction on adolescents: a systematic review of longitudinal and prospective studies. Current psychiatry reports 16, 508, doi:10.1007/s11920-014-0508-2 (2014).

34. Park, N., Kim, Y.-C., Shon, H. Y. \& Shim, H. Factors influencing smartphone use and dependency in South Korea. Computers in Human Behavior 29, 1763-1770, doi:10.1016/j.chb.2013.02.008 (2013).

35. Zisserson, R. N. \& Palfai, T. P. Behavioral Activation System (BAS) sensitivity and reactivity to alcohol cues among hazardous drinkers. Addictive behaviors 32, 2178-2186, doi:10.1016/j.addbeh.2007.02.016 (2007). 
36. Simons, J. S., Dvorak, R. D. \& Lau-Barraco, C. Behavioral inhibition and activation systems: differences in substance use expectancy organization and activation in memory. Psychology of addictive behaviors: journal of the Society of Psychologists in Addictive Behaviors 23, 315-328, doi:10.1037/a0015834 (2009).

37. Franken, I. H. A Behavioral approach system (BAS) sensitivity predicts alcohol craving. Personality and Individual Differences 32, 349-355 (2002).

38. Amodio, D. M., Master, S. L., Yee, C. M. \& Taylor, S. E. Neurocognitive components of the behavioral inhibition and activation systems: implications for theories of self-regulation. Psychophysiology 45, 11-19, doi:10.1111/j.1469-8986.2007.00609.x (2008).

39. Gray, J. R. et al. Affective personality differences in neural processing efficiency confirmed using fMRI. Cognitive, affective \& behavioral neuroscience 5, 182-190 (2005).

40. Langner, O., Becker, E. S. \& Rinck, M. Social anxiety and anger identification: bubbles reveal differential use of facial information with low spatial frequencies. Psychological science 20, 666-670, doi:10.1111/j.1467-9280.2009.02357.x (2009).

41. Haxby, J. V., Hoffman, E. A. \& Gobbini, M. I. Human neural systems for face recognition and social communication. Biological psychiatry 51, 59-67 (2002).

42. Billieux, J., Van der Linden, M. \& Rochat, L. The role of impulsivity in actual and problematic use of the mobile phone. Applied Cognitive Psychology 22, 1195-1210, doi:10.1002/acp.1429 (2008).

43. Lee, Y.-K., Chang, C.-T., Lin, Y. \& Cheng, Z.-H. The dark side of smartphone usage: Psychological traits, compulsive behavior and technostress. Computers in Human Behavior 31, 373-383, doi:10.1016/j.chb.2013.10.047 (2014).

44. Heinrichs, N. \& Hofmann, S. G. Information processing in social phobia: a critical review. Clinical psychology review 21, 751-770 (2001).

45. Ochsner, K. N., Silvers, J. A. \& Buhle, J. T. Functional imaging studies of emotion regulation: a synthetic review and evolving model of the cognitive control of emotion. Annals of the New York Academy of Sciences 1251, E1-24, doi:10.1111/j.1749-6632.2012.06751.x (2012).

46. Kerns, J. G. et al. Anterior cingulate conflict monitoring and adjustments in control. Science 303, 1023-1026, doi:10.1126/ science.1089910 (2004)

47. Kerns, J. G. Anterior cingulate and prefrontal cortex activity in an FMRI study of trial-to-trial adjustments on the Simon task. NeuroImage 33, 399-405, doi:10.1016/j.neuroimage.2006.06.012 (2006).

48. Botvinick, M. M., Cohen, J. D. \& Carter, C. S. Conflict monitoring and anterior cingulate cortex: an update. Trends in cognitive sciences 8, 539-546, doi:10.1016/j.tics.2004.10.003 (2004).

49. Etkin, A., Egner, T. \& Kalisch, R. Emotional processing in anterior cingulate and medial prefrontal cortex. Trends in cognitive sciences 15, 85-93, doi:10.1016/j.tics.2010.11.004 (2011).

50. Davidson, R. J. Affective style, psychopathology, and resilience: brain mechanisms and plasticity. The American psychologist $\mathbf{5 5}$, 1196-1214 (2000).

51. Kalin, N. H. \& Shelton, S. E. Nonhuman primate models to study anxiety, emotion regulation, and psychopathology. Annals of the New York Academy of Sciences 1008, 189-200 (2003).

52. Phillips, M. L., Drevets, W. C., Rauch, S. L. \& Lane, R. Neurobiology of emotion perception II: Implications for major psychiatric disorders. Biological psychiatry 54, 515-528 (2003).

53. Ochsner, K. N. \& Gross, J. J. The cognitive control of emotion. Trends in cognitive sciences 9, 242-249, doi:10.1016/j.tics.2005.03.010 (2005).

54. Bunge, S. A., Ochsner, K. N., Desmond, J. E., Glover, G. H. \& Gabrieli, J. D. Prefrontal regions involved in keeping information in and out of mind. Brain: a journal of neurology 124, 2074-2086 (2001).

55. Cohen, J. D. \& Servan-Schreiber, D. Context, cortex, and dopamine: a connectionist approach to behavior and biology in schizophrenia. Psychological review 99, 45-77 (1992).

56. Botvinick, M., Nystrom, L. E., Fissell, K., Carter, C. S. \& Cohen, J. D. Conflict monitoring versus selection-for-action in anterior cingulate cortex. Nature 402, 179-181, doi:10.1038/46035 (1999).

57. Carter, C. S. et al. Anterior cingulate cortex, error detection, and the online monitoring of performance. Science 280, 747-749 (1998).

58. Ochsner, K. N. et al. Deficits in visual cognition and attention following bilateral anterior cingulotomy. Neuropsychologia 39, 219-230 (2001).

59. Chun, J. W., Choi, J., Cho, H., Lee, S. K. \& Kim, D. J. Dysfunction of the frontolimbic region during swear word processing in young adolescents with Internet gaming disorder. Translational psychiatry 5, e624, doi:10.1038/tp.2015.106 (2015).

60. Ochsner, K. N., Bunge, S. A., Gross, J. J. \& Gabrieli, J. D. Rethinking feelings: an FMRI study of the cognitive regulation of emotion. Journal of cognitive neuroscience 14, 1215-1229, doi:10.1162/089892902760807212 (2002).

61. Phan, K. L. et al. Neural substrates for voluntary suppression of negative affect: a functional magnetic resonance imaging study. Biological psychiatry 57, 210-219, doi:10.1016/j.biopsych.2004.10.030 (2005).

62. Ochsner, K. N. et al. For better or for worse: neural systems supporting the cognitive down- and up-regulation of negative emotion. NeuroImage 23, 483-499, doi:10.1016/j.neuroimage.2004.06.030 (2004).

63. Beauregard, M., Levesque, J. \& Bourgouin, P. Neural correlates of conscious self-regulation of emotion. The Journal of neuroscience: the official journal of the Society for Neuroscience 21, RC165 (2001).

64. Schaefer, S. M. et al. Modulation of amygdalar activity by the conscious regulation of negative emotion. Journal of cognitive neuroscience 14, 913-921, doi:10.1162/089892902760191135 (2002).

65. Jonides, J., Smith, E. E., Marshuetz, C., Koeppe, R. A. \& Reuter-Lorenz, P. A. Inhibition in verbal working memory revealed by brain activation. Proceedings of the National Academy of Sciences of the United States of America 95, 8410-8413 (1998).

66. Song, S. et al. The influence of emotional interference on cognitive control: A meta-analysis of neuroimaging studies using the emotional Stroop task. Scientific reports 7, 2088, doi:10.1038/s41598-017-02266-2 (2017).

67. Saxe, R. \& Wexler, A. Making sense of another mind: the role of the right temporo-parietal junction. Neuropsychologia 43, 1391-1399, doi:10.1016/j.neuropsychologia.2005.02.013 (2005).

68. Saxe, R. \& Kanwisher, N. People thinking about thinking people. The role of the temporo-parietal junction in "theory of mind". NeuroImage 19, 1835-1842 (2003).

69. Lombardo, M. V., Chakrabarti, B., Bullmore, E. T., Consortium, M. A. \& Baron-Cohen, S. Specialization of right temporo-parietal junction for mentalizing and its relation to social impairments in autism. NeuroImage 56, 1832-1838, doi:10.1016/j. neuroimage.2011.02.067 (2011)

70. Etkin, A., Buchel, C. \& Gross, J. J. The neural bases of emotion regulation. Nature reviews. Neuroscience 16, 693-700, doi:10.1038/ nrn4044 (2015).

71. Fales, C. L. et al. Altered emotional interference processing in affective and cognitive-control brain circuitry in major depression. Biological psychiatry 63, 377-384, doi:10.1016/j.biopsych.2007.06.012 (2008).

72. Chun, J. W., Park, H. J., Kim, D. J., Kim, E. \& Kim, J. J. Contribution of fronto-striatal regions to emotional valence and repetition under cognitive conflict. Brain research 1666, 48-57, doi:10.1016/j.brainres.2017.04.018 (2017).

73. Hazeltine, E., Poldrack, R. \& Gabrieli, J. D. Neural activation during response competition. Journal of cognitive neuroscience 12(Suppl 2), 118-129, doi:10.1162/089892900563984 (2000).

74. Garavan, H., Ross, T. J. \& Stein, E. A. Right hemispheric dominance of inhibitory control: an event-related functional MRI study. Proceedings of the National Academy of Sciences of the United States of America 96, 8301-8306 (1999). 
75. Swick, D. \& Turken, A. U. Dissociation between conflict detection and error monitoring in the human anterior cingulate cortex. Proceedings of the National Academy of Sciences of the United States of America 99, 16354-16359, doi:10.1073/pnas.252521499 (2002).

76. van Veen, V., Cohen, J. D., Botvinick, M. M., Stenger, V. A. \& Carter, C. S. Anterior cingulate cortex, conflict monitoring, and levels of processing. NeuroImage 14, 1302-1308, doi:10.1006/nimg.2001.0923 (2001).

77. Oldfield, R. C. The assessment and analysis of handedness: the Edinburgh inventory. Neuropsychologia 9, 97-113 (1971).

78. National Information Society Agency. Development of Korean Smartphone Addcition Proneness Scale For Youth and Adults. Seoul: National Information Society Agency (2011).

79. Lee, K. U., Kim, J., Yeon, B., Kim, S. H. \& Chae, J. H. Development and Standardization of Extended ChaeLee Korean Facial Expressions of Emotions. Psychiatry investigation 10, 155-163, doi:10.4306/pi.2013.10.2.155 (2013).

80. Friston, K. J., Frith, C. D., Frackowiak, R. S. \& Turner, R. Characterizing dynamic brain responses with fMRI: a multivariate approach. NeuroImage 2, 166-172 (1995).

\section{Acknowledgements}

This research was supported by the Basic Science Research Program through the National Research Foundation of Korea (NRF) funded by the Ministry of Science, ICT \& Future Planning (NRF-2014M3C7A1062893) and the Ministry of Education (NRF-2013R1A1A2065207).

\section{Author Contributions}

D.-J.K. and J.-W.C. contributed to the conception and design of study. J.C. and J.-Y.K. contributed to the acquisition of behavioral and imaging data. H.C. undertook the clinical assessments. J.-W.C., J.C. and J.-Y.K. performed behavioral and imaging data analysis. J.-W.C. wrote the manuscript text and prepared the figures and tables. J.C., H.C., and J.-H.N. assisted with the interpretation of data and contributed to the final draft of the manuscript. H.C., K.-J.A., J.-S.C., and D.-J.K. contributed revising the manuscript critically for important intellectual content. All authors contributed to the manuscript and have approved the final manuscript.

\section{Additional Information}

Competing Interests: The authors declare that they have no competing interests.

Publisher's note: Springer Nature remains neutral with regard to jurisdictional claims in published maps and institutional affiliations.

(c) (i) Open Access This article is licensed under a Creative Commons Attribution 4.0 International

License, which permits use, sharing, adaptation, distribution and reproduction in any medium or format, as long as you give appropriate credit to the original author(s) and the source, provide a link to the Creative Commons license, and indicate if changes were made. The images or other third party material in this article are included in the article's Creative Commons license, unless indicated otherwise in a credit line to the material. If material is not included in the article's Creative Commons license and your intended use is not permitted by statutory regulation or exceeds the permitted use, you will need to obtain permission directly from the copyright holder. To view a copy of this license, visit http://creativecommons.org/licenses/by/4.0/.

(C) The Author(s) 2017 